Revista de Derecho YACHAQ

ISSN: 1817-597x (impresa) / ISSN: 2707-1197 (en linea)

Centro de Investigación de los Estudiantes de Derecho (CIED)

Universidad Nacional de San Antonio Abad del Cusco

N. ${ }^{\circ} 10-2019$

[pp. 207-219]

\title{
Entrevistas en torno a la prisión preventiva
}

\section{Interview around the Preventive Prison}

\author{
Perfecto Andrés Ibañez ${ }^{[*]}$ \\ Félix Paolo Aldea Quincho[**] \\ Germán Ramiro Alatrista Muñiz ${ }^{[* * *]}$ \\ Nataly Ugarte Molina ${ }^{[* * * *]}$
}

RESUMEN: destacados abogados defensores, fiscales y jueces a nivel nacional e internacional, brindan su punto de vista sobre el tratamiento que la prisión preventiva ha recibido en el derecho peruano; analizando su desarrollo legal y jurisprudencial, así como el uso, aparentemente desmedido, de esta medida en nuestro país.

\begin{abstract}
: leading defense attorneys, prosecutors and judges at national and international level, provide their point of view on the treatment that preventive detention has received in $\mathrm{Pe}$ ruvian law; analyzing its legal and jurisprudential development, as well as the use, apparently excessive, of this measure in our country.
\end{abstract}

PALABRAS CLAVE: prisión Preventiva. Derecho a la libertad. Medida cautelar excepcional. Populismo punitivo. Uso desmedido.

KEY WORDS: preventive prison. Right to freedom. Exceptional precautionary measure. Punitive populism. Excessive use.

[*] Magistrado emérito de la Sala Segunda del Tribunal Supremo de España y Director de Jueces para la Democracia, Información y debate. Ex presidente de sección en la Audiencia Provincial de Madrid. Juez de instrucción y de primera instancia en diversas ciudades españolas. Ex vocal del Consejo General del Poder Judicial. - Fundador y director de la revista "Jueces para la Democracia. Información y debate".

[**] Paolo Aldea. Abogado por la Universidad Nacional de San Antonio Abad del Cusco. Master Universitario en Derecho Constitucional por la Universidad de Castilla - La Mancha (España). Doctorando en Derecho y Ciencia Política por la Universidad Nacional Mayor de San Marcos. Estudios Avanzados en Sistema Interamericano de Protección de los Derechos Humanos y Derecho Internacional Humanitario en la America University College of Law (Washington DC). Senior Partner del Estudio Paolo Aldea, Reategui, Nakazaki y Chino Abogados.

[***] Abogado por la Universidad Nacional San Antonio Abad del Cusco, Ex Fiscal Penal, conferencista, abogado penalista, Gerente Legal del Estudio Alatrista \& Muñiz Abogados Asociados.

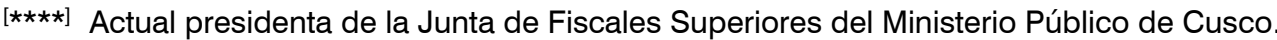




\section{PRELIMINAR}

Perfecto Andres Ibañez: No me parece posible afrontar con un mínimo de racionalidad y rigor las preguntas de esta entrevista, sin fijar algunos presupuestos previos.

El primero es que la vigencia de la prisión provisional, en el marco de una disciplina constitucional del proceso inspirada en el principio de presunción de inocencia, representa una aporía insalvable. Porque priva del derecho fundamental a la libertad, imponiendo lo que es materialmente una pena, a quien no ha sido declarado culpable. Y lo hace, no de la forma interina que parece sugerir el propio nomen, sino de forma definitiva. Por eso, su aplicación, en realidad, equivale a una condena preventiva. Esta constatación, por demás elemental, podría ilustrarse de muy diversas maneras, pero me parece que basta señalar, por su expresividad, lo acontecido en el marco de la Asamblea Constituyente que alumbró la Constitución italiana de 1948, donde, para evitar o atenuar las dificultades de compatibilidad de la primera con la segunda, se optó por una fórmula menos comprometedora. Así, se consagró, no la presunción de inocencia, sino la de no culpabilidad hasta la condena definitiva (artículo 27).

El segundo presupuesto es que, dígase de ella lo que se diga, lo que ciertamente expresa la prisión provisional como medida, es un (pre) juicio o pronóstico de condenabildad. Por eso, sea cual fuere el fundamento de que se dote a la resolución que la adopte, y, por más que se ponga el acento en finalidades procesales, las que general y realmente cuentan son de carácter sustantivo. En particular: comenzar a castigar, saliendo de este modo al paso de la difusa demanda de rigor represivo que sigue normalmente a la producción de alguna clase de delitos, conteniendo la alarma social.

El tercer presupuesto es que, hoy, la prisión provisional ocupa un lugar preeminente, si no el centro mismo del sistema penal. Tanto es así que, en muchos casos y frente a aquellas categorías de delitos que generan especial preocupación (espontánea o inducida) en la ciudadanía, pesa más en la opinión de esta el encarcelamiento preventivo inmediato que la futura condena.
En fin, una última consideración: es obvio que las decisiones judiciales en la materia de que se trata deben ser fundadas, pero también lo es - y hablo por experiencia- que no existen resoluciones más difíciles de motivar, ni que dejen más insatisfecho al que las adopte, a poco que tenga alguna sensibilidad crítica y autocrítica. Por eso he sostenido en alguna ocasión, que la mala conciencia del juez podría/debería ser la última garantía no escrita en la aplicación de esta medida nada limpia.

1. En el plano peruano, existe amplio debate sobre la prisión preventiva y sus presupuestos materiales. ¿Considera que la prisión preventiva ha recibido un adecuado desarrollo normativo a nivel de legislación y jurisprudencia?

Nataly Ugarte Molina: En mi opinión, sí. La prisión preventiva, normativamente, está debidamente reglamentada en el Código Procesal Penal. A nivel de jurisprudencia también, estos 15 años de vigencia del Código Procesal Penal han hecho que la Corte Suprema siempre este resolviendo temas en los que se han advertido ambigüedades, más aún cuando los temas en el derecho son muy dinámicos, por ello, pienso que, en adelante, vamos a tener que seguir recurriendo a ella.

Félix Paolo Aldea Quincho: Considero que se ha intentado dar un adecuado desarrollo normativo, sobre todo a nivel de jurisprudencial, a través de los últimos pronunciamientos de la Suprema Corte; pero es preciso resaltar que esta institución jurídica ha estado sujeta a constantes pronunciamientos contradictorios, relacionado con temas tales como la procedencia o no de poder discutir en audiencia tópicos sobre Tipicidad, Imputación necesaria, validez del medio de prueba, entre otras.

Por otro lado, resulta utópico pensar que una casación o un acuerdo plenario pueden combatir el uso y abuso, por parte de los jueces, de la aplicación de esta medida tan gravosa para la libertad. La solución no radica en el desarrollo argumentativo o la buena construcción gramatical que el órgano supremo plasma en un papel; por el contrario, la sustancia del problema se encuentra en la forma como los jueces interiorizan y aplican los principios de la prisión preventiva, en el caso en concreto. 
Germán Ramiro Alatrista Muñiz: En la página del INPE, en su módulo estadístico, sobre la situación actual de la capacidad de albergue y sobrepoblación, a marzo del 2019, se tiene la siguiente data: que en el establecimiento penitenciario de Cusco, se tiene una capacidad de albergue para 2918 reclusos, pero la población penal es de 5552 reclusos, existiendo una sobrepoblación de 2634 reclusos.

Y esto sucede en todas las regiones del país, la capacidad de albergue es altamente inferior a la población actual en los centros penitenciarios; el cual implica inferir que los centros penitenciarios tienen un alto número de hacinamiento.

En la Casación № 626-2013- Moquegua se ha establecido que para imponer la medida coercitiva de prisión preventiva, debe acreditarse mediante datos objetivos obtenidos preliminarmente y/o propiamente de investigación que cada uno de los aspectos de la imputación tenga una probabilidad de ser cierta. La sanción a imponerse sea superior a cuatro años de pena privativa de libertad.

En el presupuesto de peligro de fuga, el Juez tendrá en cuenta, el arraigo en el país del imputado, determinado por el domicilio, entre otros. Respecto del peligro de obstaculización se tendrá en cuenta el riesgo razonable de que el imputado: influirá para que coimputados, testigos o peritos informen falsamente o se comporten de manera desdeal o reticente, entre otros. Pero no es posible que un simple imputado pueda manipular todas estas circunstancias.

La legislación es adecuada y parece ser precisa al exigir el cumplimiento de estos requisitos, sin embargo en el Perú los fiscales en algunos casos politizados, aun cuando no se cumple con las condiciones para ser dictada esta medida, pero por ser mecánicos en los procedimiento y el cumplimiento de las normas procesales, solicitan para todas las personas aun sin considerar que es casi imposible que un ciudadano de a pie, pueda estar inmerso en el tercer requisito, que tratará de eludir la acción de la justicia (peligro de fuga) u obstaculizar la averiguación de la verdad (peligro de obstaculización).

Jurisprudencialmente la Casación №626-2013 Moquegua, siendo la más importante, establece la motivación y elementos de la prisión preventiva, en el cual se señala que la audiencia de prisión pre- ventiva se dividirá necesariamente en cinco partes, de modo que se aborden i) primer presupuesto; ii) segundo presupuesto; iii) tercer presupuesto; iv) proporcionalidad; y v) duración de la medida. Se ejercerá contradicción punto por punto y solo agotado un tema, se pasará al siguiente. Esto posibilitará que el juez analice y resuelva cada uno.

2. La Corte Suprema peruana ha establecido que el nivel de sospecha para requerir prisión preventiva se encontraría entre el exigido para el requerimiento acusatorio y la sentencia condenatoria. ¿Es posible aplicar la prisión preventiva de conformidad a este estándar, cuando, generalmente, la medida se da al inicio de la investigación preparatoria? ¿Bajo este estándar, tiene sentido exigir este nivel de sospecha cuando la medida se requiera por peligro de obstaculización de la averiguación de la verdad, si se supondría que se ha averiguado lo suficiente para acusar?

Perfecto Andrés Ibáñez: El estándar, es obvio, resulta en extremo impreciso. Pero, estando a su formulación, diría que no me parece imposible que, dependiendo de la naturaleza del delito y de las circunstancias del caso, ya en el inicio de la investigación, pudiera contarse con un relevante elenco de indicios fuertemente sugestivos de la implicación del denunciado o imputado. En cuanto a la segunda cuestión, si el criterio determinante de la medida tuviera que ser, de manera exclusiva, el de la protección de la integridad del cuadro probatorio, una vez asegurada esta, dejaría de haber causa para la privación cautelar de libertad.

Nataly Ugarte Molina: Si se requiriese un nivel de sospecha casi certero para solicitar prisión preventiva, entonces no tendría mucho sentido que la fiscalía formalice investigación preparatoria. Este nivel de sospecha implica que el fiscal este convencido de la comisión del delito y que el responsable es la persona a quien está investigando; si eso fuera así, nuestra investigación estaría concluida, no tendría ningún sentido que continuemos investigando, aun preparatoriamente, tendríamos que optar, probablemente, por un proceso inmediato o por una acusación directa. 
Ahora bien, la fiscalía se guía por la casación № 626-2013 Moquegua. En esta casación la Corte Suprema, señala que, para solicitar prisión preventiva, se requiere, solamente, un alto grado de probabilidad, no dice que los niveles de sospecha sean una certeza absoluta de la comisión del delito y de la responsabilidad de la persona que estamos investigando. De igual manera los jueces, para resolver un pedido de prisión preventiva, emplean la casación № 626-2013 Moquegua.

Ahora, cuando la casación dice que haya un alto grado de probabilidad, nosotros entendemos, que, en primer término, para pedir una prisión preventiva, la investigación tiene que estar formalizada, ese es el primer presupuesto, y casi paralelamente o más adelante pedimos la prisión preventiva. $Y$ ¿Cuándo disponemos la investigación preparatoria? Cuando haya causa probable, así lo ha señalado el Tribunal Constitucional. Para nosotros la causa probable, es que, investigados los hechos, los elementos de convicción recabados por el fiscal arrojen que sí se ha cometido el delito, es decir, la comisión del delito es incuestionable. Del mismo modo, la responsabilidad del investigado también tiene que tener soporte a partir de los elementos de convicción, es decir, que, de la cantidad y calidad de elementos de convicción acopiados por el Fiscal, al momento en el que se dispone la formalización de la investigación preparatoria, den como resultado que la persona que estoy investigando si es la responsable de la comisión de ese delito; esto es la alta probabilidad. No hay una certeza absoluta, porque si la tuviera, no tendría ningún sentido que el fiscal siga investigando preparatoriamente, tendría que emitir una acusación directa o recurrir a un proceso inmediato.

Félix Paolo Aldea Quincho: En relación con la primera pregunta, sí es posible, dado que para solicitar una medida de coerción como lo es la prisión preventiva se requiere desde la formalización una imputación provisional, si bien es cierto, no tan exhaustiva o acabada como sí lo amerita una acusación, pero sí que cumpla con estándares mínimos que permitan identificar los elementos nucleares de la imputación y sus soportes fácticos. Este último punto, cuando menos debería de estar dirigido a agotar el examen de subsunción típica, en tanto que este, forma los temas de prueba de la imputación fiscal, de la participación del sujeto pasivo de la medida.
El nivel de sospecha de la vinculación existente es lo que determina la medida de prisión preventiva.

Respecto a la segunda interrogante, sí tiene sentido exigir la imposición de esta medida, con el estándar establecido, debido a que las investigaciones son dinámicas; por lo tanto, si puede existir la posibilidad de que el imputado trate de obstaculizar la averiguación de la verdad en el decurso de las investigaciones y del proceso. Adicionalmente a esto, un argumento, si bien principista pero igualmente válido, es que se debe recordar que una persona solo debe afrontar cárcel cuando se ha probado su responsabilidad más allá de cualquier duda razonable, regla básica y fundamental en la fundamentación del Estado de Derecho, por lo que el romper una regla así de medular implica que su justificación sea igual de relevante.

Germán Ramiro Alatrista Muñiz: En la sentencia plenaria $\mathrm{N}^{\circ}$ 01-2017/ClJ-433 establece como grados de sospecha inicial simple, determinar si han tenido lugar los hechos objeto de conocimiento y su delictuosas, así como asegurar los elementos materiales de su comisión, individualizar a las personas involucradas en su comisión y dentro de los límites de la ley, asegurarlas debidamente.

Para la expedición de la disposición de formalización de la investigación preparatoria se necesita sospecha reveladora, esto es, indicios reveladores de la existencia de un delito, que la acción no ha prescrito, que se ha individualizado al imputado y que si fuera el caso, se han satisfecho los requisitos de procedibilidad.

Para la formulación de la acusación y la expedición del auto de enjuiciamiento se precisa sospecha suficiente, vale decir, tener base suficiente para ello o elementos de convicción suficientes para solicitar fundadamente el enjuiciamiento del imputado.

Considero que no debe de darse esta medida en la investigación preparatoria, porque solo se estaría en la etapa de investigación, y muchas veces las investigaciones de los fiscales son deficientes, sin cumplir con todas las condiciones necesarias para ser dictadas.

Pues se ha adoptado un sistema garantista que ha regulado la institución de la prisión preventiva teniendo como base el respeto a la presunción 
de inocencia. Pues el trato que se da a la prisión preventiva no implica un adelantamiento de pena, en tanto se la impone, no por razones de prevención general o especial positiva o negativa o de retribución (que son los fines clásicos de la pena) sino por razones de peligro procesal.

Entonces si la prisión preventiva se basaría en algún fin de la pena se estaría violando el derecho a la presunción de inocencia, por lo que no se puede fundamentar la prisión preventiva por que el procesado posiblemente vaya a cometer otro delito (prevención).

Carece de justificación que en un estado democrático se limite derechos fundamentales, sin las debidas y justificadas exigencias.

3. La Corte Suprema ya se ha pronunciado sobre el análisis de tipicidad como parte de la imputación necesaria en el análisis relacionado a los graves y fundados elementos de convicción. ¿Los tribunales deberían permitir el debate sobre cuestiones referidas al resto de elementos del delito como parte del análisis de concurrencia del primer presupuesto de esta medida, o incluso resolverlas de oficio?

Perfecto Andrés Ibáñez: Entiendo que sí, que, dada la gravedad de la medida, en presencia de elementos de juicio, obviamente también provisionales, sugestivos de que pudiera faltar algún elemento relevante del delito o jugar alguna causa de justificación o de inculpabilidad, esto debería tomarse en consideración en el momento de decidir.

Nataly Ugarte Molina: Discrepo que en una audiencia de prisión preventiva tengamos que discutir temas de tipicidad; primero, porque el hecho de que el fiscal solicite al juez se dicte esta medida respecto a uno de los investigados, implica que se está señalando que esa persona ha cometido un delito y se tienen los presupuestos que exige el Código Procesal Penal para que dicte la prisión preventiva; es decir, la prognosis de pena, que hay suficientes elementos de convicción que vinculen a la persona investigada con el delito, que hay un peligro procesal, ya sea peligro de fuga o peligro de obstaculización, y, además, considerando la casación № 626-2013 Moquegua, que hay proporcionalidad en la medida.
Entonces, ¿Que debe hacer el juez en una audiencia de prisión preventiva? Resolver el pedido de prisión preventiva, ceñirse a que el fiscal acredite que están los cinco presupuestos y, si considera que esos cinco presupuestos concurren entonces la dictará, este es el objetivo en sí.

La discusión sobre el análisis de la tipicidad en el pedido de prisión preventiva, ya se ha dado, un ejemplo es el caso Walter Ríos. En este caso, el abogado solicito discutir los temas de tipicidad en el caso concreto, ya que los hechos no se adecuaban al tipo penal imputado. Ahora, ¿Debería el juez resolver el tema de tipicidad para resolver el pedido de prisión preventiva? ¿Debería introducirse en debate el tema de tipicidad? Según mi criterio personal, no, puesto que, en el supuesto que el juez permita el debate sobre la tipicidad, y como resultado de este se concluya que la conducta constituye un delito o no, estaríamos frente a un adelantamiento de opinión, y en esa etapa -el inicio de la investigación preparatoria- no se puede adelantar opinión.

Cierto es que la corte suprema en el caso Walter Ríos ha dicho que en determinados casos si se podría discutir los temas de tipicidad; concretamente, en los casos en el que fiscal concluya la etapa de investigación preliminar, decida formalizar investigación preparatoria y, de manera simultánea, solicite la prisión preventiva; este es un hecho que ocurre en la práctica, porque en la disposición de formalización de la investigación preparatoria se tiene que precisar la condición del imputado. Lo que paso en el caso de Walter Ríos fue que el fiscal al emitir la disposición de formalización de investigación preparatoria, solicita, de manera simultánea, la medida de prisión preventiva al juez; no obstante, al imputado se le notifico únicamente la solicitud de prisión preventiva, de ahí que el día de la audiencia, al abogado y al imputado solamente tenían conocimiento de la solicitud de prisión preventiva, esto provoco que se cuestionara que la conducta no se adecuaba a un tipo penal.

De ahí que la Corte Suprema señala que, en un escenario como este, si se debería discutir la tipicidad del delito en una audiencia de prisión preventiva. Contrario sensu si al imputado se le ha notificado la disposición de formalización de la investigación preparatoria y ha tenido el tiempo ra- 
zonable para cuestionar la conducta y temas de la tipicidad de la conducta, no se les acepta porque su cuestionamiento tiene su propio canal, que en el caso de tipicidad es la improcedencia de la acción.

Félix Paolo Aldea Quincho: Considero que si debería existir un debate respecto a todos los elementos del delito como parte del análisis de la concurrencia del primer presupuesto, porque los graves y fundados elementos de convicción deben estimar razonablemente la comisión de un DELITO, el mismo que cuenta con las siguientes categorías materiales: Tipicidad, Antijuricidad, Culpabilidad y Punibilidad. En otras palabras, es imposible que un hecho no delictivo o una imputación vaga e imprecisa que no logre pasar por el primer filtro de la tipicidad, sea utilizado para la solicitud de una medida tan intensa y grave.

Germán Ramiro Alatrista Muñiz: La incorporación de puntos de debate, y la exigencia de motivación exhaustiva en el requerimiento fiscal. Es ante esta situación, que la audiencia de prisión preventiva se convierte en el escenario ideal para la discusión de tipicidad que no pudo realizarse antes por la notificación simultánea de la disposición de formalización y el requerimiento de prisión en el mejor de los supuestos. En una audiencia de prisión preventiva sí podrían discutirse cuestiones de tipicidad, esto será objeto de otro análisis más extenso; planteamos que la permisibilidad del debate en una audiencia de prisión preventiva, respecto de la tipicidad de los hechos, podrá depender de si en el caso, existió o no la posibilidad de que la defensa haya podido.

4. ¿Debería aprobarse el proyecto de ley que propone criminalizar a fiscales y jueces que requieran y dicten la prisión preventiva indebidamente?

Perfecto Andrés Ibáñez: Si, acordar una prisión provisional es siempre disponer una medida, como he dicho, connotada de algún grado de ilegitimidad; hacerlo sin fundamento legal solo puede ser prevaricador. Por tanto, la conducta correspondiente no debería pasar sin sanción, adoptada, es obvio, de resultar procedente, en un marco de garantías sustantivas y procesales.

Nataly Ugarte Molina: No. Tenemos un delito específico que es el prevaricato para que se penalice por ahí, que se criminalice, me parece que es intimidatorio para los magistrados, no debe haber injerencias, sería una afectación absoluta a la independencia del juez y fiscal. Sería excesivo.

Félix Paolo Aldea Quincho: La criminalización de ciertas conductas humanas, a veces, no es la solución para enfrentar o detener una mala práctica constante, en el presente caso, por algunos jueces y fiscales, quienes no realizan una adecuada labor. Bajo ese argumento, no debería aprobarse dicho Proyecto, porque la sanción penal debe ser utilizada como última razón y no utilizada como única solución. Por el contrario, debería existir mayor compromiso y apoyo para la capacitación constante de aquellos funcionarios, quienes, a veces, no logran entender el cargo que ejercen y actúan como un ciudadano más de a pie.

Germán Ramiro Alatrista Muñiz: En resumen, lo que señala este proyecto de ley en su artículo 5 es que, si el juez o fiscal que dicte prisión preventiva o emita la solicitud pertinente no consigne los fundamentos de hecho o de derecho, u ordene la medida desproporcionalmente, recibiría hasta 10 años de cárcel.

Este proyecto de ley está relacionado al criterio de los fiscales y jueces que tiene para la decisión de determinar los elementos de convicción, se podría decir; que se va a penalizar algo que proviene de un ámbito subjetivo, de la conciencia de los jueces y fiscales, pero se tiene una normativa procesal que nos permite ver en qué dirección deben estar ciertos actos de jueces y fiscales, y en el caso de la prisión preventiva determinar observar si se cumple con los presupuestos o no para dictar dicha medida.

Considero que es una buena medida; sin embargo, la aplicación de la misma debe ser progresiva, iniciar por los departamentos con mayor índice del uso de prisión preventiva o de los juzgados con mayor índice donde se dictó esta medida.

5. Se dice que existe un uso desmedido de la prisión preventiva, ello a razón de los recientes sucesos en los que se han visto involucrados altos funcionarios y ex funcionarios públicos de nuestro país. ¿Usted concuerda con esta afirmación? ¿El uso desmedido de la prisión preventiva encuentra alguna justificación?

Perfecto Andrés lbáñez: Si el recurso a la prisión provisional no puede dejar de ser problemático en el plano de los principios, por más que resulte 
constitucional, el uso desmedido de la misma disparará exponencialmente la incidencia de ese factor. Por tanto, ¿cómo podría estar justificado? Pero, no puedo dejar de decirlo: me resulta sospechoso el ataque de sensibilidad garantista que parece haber embargado a connotados opinantes peruanos. A aquellos cuya preocupación por los abusos de la prisión provisional ha nacido al afectar está a ciertos imputados excelentes. Mientras, siguen sin saber del modo, siempre generoso, en que lo hace tratándose del imputado de a pie.

Félix Paolo Aldea Quincho: Sí, concuerdo con esta afirmación, la realidad y la práctica así lo demuestran. La única justificación que debe existir para la imposición de esta medida debería ser lo expresado por nuestra norma adjetiva; esto es el cumplimiento de los presupuestos materiales previsto en el artículo 268 CPP, y los pronunciamientos de los órganos supremos. Cualquier justificación que no sea razonable y proporcional, al caso en concreto; es decir, que no guarden relación con los parámetros, principios que la constitución señala deben ser anuladas. Este problema, si bien es apreciado por toda la sociedad por la persona que enfrenta la medida, este es un tópico de relevancia nacional tanto por lo que implica que una sola persona se vea afectada sin motivo alguno así como por el alto porcentaje de presos, en calidad de preventivos, que existe en nuestra población carcelaria; esto dos aspectos han sido ya materia de observación y pronunciamiento a manera de soft law por parte de la CIDH.

Germán Ramiro Alatrista Muñiz: Existe este abuso desmedido de la prisión preventiva, dictándose indebidamente y violentando los derechos de los imputados.

Primero, cabe señalar que no aplicar la prisión preventiva no es igual a decir que haya impunidad porque no es un tipo de sanción, pese a que la opinión pública lo considere de ese modo. Sin embargo; en la legislación penal peruana, el tema de la prisión preventiva es latente y un tema de todos los días en los juzgados; y este conflicto se inicia con la reforma del proceso penal, siendo más específicos con la entrada en vigencia del Nuevo Código Procesal. Y pese a que este nuevo modelo procesal ha implicado numerosos cambios enmarcados en el respeto de las garantías procesales, no ha significado un avance en cuando a la protección desmedida de la prisión preventiva.

El factor que considero relevante en el uso excesivo de la prisión preventiva es la política criminal peruana que está basada en la sobre criminalización, donde la pena siempre es superior a los 4 años.

Otro factor es la falta de proporción entre la duración de la eventual pena y de la medida cautelar. La Comisión Interamericana en su Informe $\mathrm{N}^{\circ}$ $86 / 09$, afirmó que la medida cautelar no debe igualar a la pena, en cantidad ni en calidad.

La proporcionalidad se refiere justamente a eso, se trata de una ecuación entre el principio de inocencia y el fin de la medida cautelar. No se trata de una equivalencia.

De una óptica de la política criminal y de la seguridad, se advierte que los problemas del uso desmedido de la prisión preventiva no son resueltos por el endurecimiento de las penas, sin encontrar hasta hoy un camino o propuestas que mejoren esta situación.

6. ¿La presión social influye en la decisión que puedan tomar los fiscales o jueces respecto al pedido $u$ otorgamiento de la prisión preventiva? ¿Existe populismo punitivo judicial al momento de resolver los requerimientos?

Perfecto Andrés Ibáñez: Lamentablemente, los medios de comunicación, sobre todo algunos, suelen convertirse en instancias de expresión de actitudes y demandas justicialistas, movidas por intereses nada o poco confesables. $Y$ es sabido que lo buscado es condicionar la opinión de sectores sociales fácilmente influenciables. Y también, cómo no, las actitudes de los jueces. Estos, por razón de cultura y de oficio, deberían ser impermeables a tal clase de sugestiones, pero, lamentablemente, en muchos casos no es así. Por lo demás, creo haberlo anticipado, es claro que, en nuestras sociedades, la prisión provisional está desempeñando en gran parte las funciones reservadas a la pena.

Nataly Ugarte Molina: El fiscal cuando solicita la prisión preventiva la resuelve en base a su carpeta fiscal que contiene los elementos de convicción, si la investigación hasta el momento da como resultado que el delito se ha cometido, que existen indicios 
que indicar su responsabilidad y concurren los presupuestos, se solicitará. Los fiscales estamos libres de injerencias, estamos libres de ello y lo hacemos en base a los elementos de convicción.

Félix Paolo Aldea Quincho: Nuestra realidad, con los famosos casos emblemáticos, demuestran que sí existe una influencia, pérdida de imparcialidad por parte de nuestros funcionarios. Al parecer el reclamo social es una gran corriente que orienta el curso de las decisiones y actuaciones ejercidas por los jueces y fiscales. Esto, se ve como parte de un mal mucho más profundo que aqueja a todo nuestro sistema de justicia; la falta de estabilidad y seguridad que tienen los operadores jurisdiccionales del sistema respecto de las plazas que ocupan. El no saber si tu decisión va a permitirte seguir con un trabajo, hace que uno termine inclinándose para la opinión menos controvertida.

Germán Ramiro Alatrista Muñiz: El populismo punitivo puede definirse como un conjunto de medidas legislativas de corte penal que privilegian las demandas mayoritarias expresadas por la opinión pública, las víctimas y los sectores sociales que se identifican como potenciales víctimas, por sobre los límites normativos consagrados en las constituciones liberales.

La decisiones judiciales o fiscales parecen estar sesgadas por una fuerte tendencia global orientada a privilegiar los intereses de las mayoritarias por sobre los límites que suponen los valores consagrados en las constituciones liberales; desconociendo el primer objetivo exigido por las doctrinas de justificación del castigo de base utilitarista, la prevención de delitos, y a través de ello la protección de los bienes jurídicos. Las políticas de mano dura aparecen como un instrumento de negociación con las mayorías con la única finalidad de la conservación del poder político.

Al reflexionar sobre las circunstancias que nos han inducido a expandir ilimitadamente el sistema penal, sobre criminalizar las actividades de las personas; y no como excepción, identificamos que el haber consentido que hacer justicia es castigar y no discernir la verdad, nos ha acostumbrado a la violencia que la orden de detención implica y al morbo de la lucha desigual entre el Estado y el infractor, que culmina con la inexorable derrota de éste, al que se le impone una pena perdida, en el sentido que el Estado desaprovecha una oportunidad para recuperar a la persona.

\section{7. ¿La politización de la medida de prisión preventiva en nuestro país, que la cataloga como "persecución política" ha afectado la labor fiscal y judicial? ¿De qué manera?}

FélixPaoloAldeaQuincho:Indiscutiblemente la prisión preventiva se ha politizado, si no es la gran mayoría de casos, si en los llamados "casos emblemáticos"; aunque creo que debe de hacerse la distinción respecto del rol que cumple cada uno de los jugadores. Por un lado, Fiscalía pareciera llevar un ritmo absolutamente diferente respecto de los partidos políticos con menos enfrentamiento al gobierno que respecto de aquellos que, con justa razón o sin ella, mantenga una línea de oposición; esto cuando menos, evidenciaría una tendencia de sesgo ideológico por parte de esta entidad. Con relación al Poder Judicial, me remitiría a mi respuesta anterior.

Germán Ramiro Alatrista Muñiz: El Informe sobre medidas dirigidas a reducir el uso de la prisión preventiva en las Américas aprobado por la Comisión Interamericana de Derechos Humanos el pasado 3 de julio de 2017 enfatiza la importancia de que los estados, con la finalidad de racionalizar el uso de la prisión preventiva y, por consiguiente, de hacer frente al hacinamiento carcelario, regulen, implementen, supervisen y promuevan la aplicación de las medidas alternativas a la prisión preventiva.

Asimismo, señala que las reformas legales que proponen mayores niveles de encarcelamiento como (pseudo) solución a los problemas de seguridad ciudadana, vienen acompañadas de un fuerte mensaje mediático y político que cuentan con un gran respaldo de la opinión pública, obstaculizando con ello la adopción de iniciativas tendientes a racionalizar el uso de la prisión preventiva. Estas reformas se traducen, principalmente, en el incremento de la duración de la prisión preventiva.

En suma, la Comisión reitera que los estados de la región deben adoptar las medidas judiciales, legislativas, administrativas y de otra índole, que se requieran a fin de corregir la excesiva aplicación de la prisión preventiva; destacando entre estas me- 
didas, la aplicación de las medidas alternativas a la prisión preventiva. En este sentido, los estados tienen la obligación de garantizar que la prisión preventiva sea de carácter excepcional y se encuentre limitada por los principios de legalidad, presunción de inocencia, necesidad y proporcionalidad.

La prisión preventiva, como se viene aplicando en la actualidad, atenta gravemente con principios cardinales de un Estado social, democrático y de Derecho, tales como la presunción de inocencia, el debido proceso, a la libertad, entre otros, y no por la decisión abusiva e irresponsable de algún magistrado indolente y razonable, sino porque el uso excesivo y colosal del ius puniendi, del cual la prisión preventiva es una expresión, está inscrito en un paradigma cultural y político que relega los derechos fundamentales y los subordina al cumplimiento de otros fines utilitarios, pragmáticos y efectistas, que producen inmediatos beneficios políticos en el ámbito de la opinión pública.

8. ¿Qué repercusiones podría acarrear, en la justicia penal peruana, las modificaciones realizadas a este instituto jurídico procesal (prolongación del plazo de duración, la creación de la figura de adecuación de la prolongación y diferenciación del plazo en caso de delitos cometidos por funcionarios y en organización criminal)?

Perfecto Andrés Ibáñez: Siempre dentro de la lógica del sistema, la condición de sujeto público del imputado y la posible implicación en una organización criminal, podrán ser factores que - aparte de dotar a la conducta infractora de una especial gravedad- obstaculicen la persecución y hagan más difícil el acopio del material probatorio eventualmente de cargo. En este sentido, la ampliación del plazo de duración de la medida podría no resultar injustificada. Pero estas son circunstancias que deberían contar con un principio razonable de acre- ditación, intersubjetivamente valorable, y no operar como meras invocaciones rituales.

Sobre la repercusión de estos criterios en la práctica de la jurisdicción peruana, me resulta imposible pronunciarme.

Nataly Ugarte Molina: Todos sabemos que la carga procesal en el Ministerio Publico es excesiva y esto, a largo plazo, hace que los fiscales se dejen ganar con los plazos. Por ello, el hecho de que haya la figura de prolongación de prisión preventiva, implica un respiro para la fiscalía, porque va a permitirle concluir sus investigaciones. Lo que antes pasaba, es que no concluíamos las investigaciones y nos planteaban el famoso control de plazos. A través de esta medida de control, los jueces, fijaban un plazo para que los fiscales se pronuncien, incluso si nos encontrábamos a la mitad de las investigaciones y, esto, ha significado, en muchos casos, impunidad, ya que, con plazos cortos, el fiscal no podía agotar la investigación, y no se permitía acreditar que el hecho se cometió y que el responsable es el investigado. Pareciera una justificación, pero en la práctica es así, en fiscalía no hay una correspondencia razonable entre el número casos fiscales y el número de fiscales.

En cuanto al tema de la adecuación de plazos, del mismo modo, considero que es positivo. Esta figura nos permite manejar los tiempos y concluir nuestras investigaciones. Además, habría que precisar que la adecuación no es un plazo adicional o una redefinición de plazos en la investigación, solamente es una adecuación del pazo de prolongación. Asimismo, se recurre a la adecuación del plazo porque el fiscal sustenta una especial dificultad en las investigaciones, por ejemplo, cuando se haya incluido en las investigaciones a una pluralidad de investigados o se han incluido más hechos. Por eso la repercusión de la incorporación de estas figuras, para nosotros, ha sido positiva, puesto que, permiten adecuarnos a las necesidades que surgen en el trascurso de la investigación. 


\section{PREGUNTAS ESPECÍFICAS}

\section{PERFECTO ANDRÉS IBÁÑEZ}

1. ¿Considera que la detención preliminar y la prisión preventiva son utilizadas como estrategias de investigación, o peor aún, como estrategias para conseguir colaboradores eficaces en los casos de alta criminalidad?

Creo que hay suficiente experiencia de qué es lo que se da en muchos casos. Pero no solo cuando se trata de alta criminalidad. Como puso ejemplarmente de manifiesto Miranda vs. Arizona, tal es una de las habituales formas de $(a b)$ uso de la prisión provisional.

2. ¿Qué opina de la posición prevalente que tienen la gravedad del delito y de la pena, y la pertenencia a una organización criminal como supuestos que motivan la imposición de prisión preventiva de manera casi automática, dejando de lado las características personales y la situación del procesado?

Dentro, obviamente, de la lógica del sistema, es claro que esos indicadores serán, sin duda, relevantes para decidir. Pero también entiendo que, al hacerlo, tendría que huirse de cualquier forma de automatismo, y ampliar la consideración a esos otros elementos de juicio que se indican.

3. ¿Qué opinión le merece la prisión preventiva de oficio y las ultimas modificatorias mexicanas?

Históricamente, en los países con legislaciones procesales de ascendencia napoleónica, la posibilidad de adoptar de oficio la prisión provisional era una de las genuinas atribuciones del juez de instrucción. Ha sido también una de las razones de la puesta en cuestión de esta figura. Por coherencia con el punto de vista que he expresado sobre la prisión provisional, creo que resulta exigible que su adopción se produzca a instancia de parte, normalmente, del ministerio fiscal, y que la solicitud sea examinada de forma pública y contradictoria.
De las medidas recientemente adoptadas en México no tengo más información que la de la prensa. Al respecto, insistiré en que no me convence en absoluto la imposición legal del automatismo en la adopción, cuando se trate de ciertos delitos. La situación de este país, en materia de delincuencia, es ciertamente aterradora, pero creo que esa clase de políticas hiperpenalizadoras corren el riesgo de quedar en mera propaganda, porque no inciden en la raíz de los fenómenos delincuenciales que se trataría de combatir.

\section{4. ¿Es posible un proceso penal sin prisión preventiva?}

Si hubiera que responder con un monosílabo, diría que sí. Naturalmente, en hipótesis, y solo a partir de una deconstrucción y reconstrucción sobre nuevas bases del sistema socio-económico, y jurídico-político que hoy la hace necesaria. En definitiva, de una transformación revolucionaria del estado de cosas. Lo que hay, no es una imposibilidad ontológica, sino una dificultad decididamente política.

\section{NATALY UGARTE MOLINA}

1. ¿Cuáles son las medidas alternativas que permiten que la persona imputada se encuentre en libertad mientras se tramita el proceso penal? ¿En verdad funcionan?

Las medidas alternativas son la comparecencia simple, la comparecencia con restricciones donde el juez impone varias reglas de conducta, el arresto domiciliario entre otros, de acuerdo a la edad que tienen los investigados. ¿Funcionan? En el caso de la comparecencia simple creo que no hay ningún problema porque normalmente se dicta para efectos más simples; por ejemplo, están las estafas en agravio de una sola persona, están las apropiaciones ilícitas, es decir, delitos con penas leves. En cuanto a la comparecencia con restricciones, ahí sí tengo mis reparos y especialmente lo he visto en mi experiencia como fiscal superior antico- 
rrupción, en Cusco no se ha dado muchos casos en temas de prisión preventiva en delitos de corrupción de funcionarios, casi siempre le dan comparecencia con restricciones, ha funcionado este tema en anticorrupción, la respuesta es que no, no han cumplido con las reglas de conducta, entonces he visto que los fiscales están pidiendo la revocatoria de la comparecencia con restricciones para que se varíe con prisión preventiva, ahora como experiencia personal no he visto un solo caso en Cusco con arresto domiciliario. Entonces cuando se revoca a prisión preventiva, sólo así se están sometiendo al proceso, esta revocatoria tiene sus presupuestos y dice por incumplimiento de reglas de conducta, claro que la Corte Suprema ha añadido la existencia de hechos nuevos.

2. ¿La prisión preventiva, es usada actualmente como una medida anticipada más que como una medida cautelar? ¿De ser así, se podría prescindir del peligro procesal?

La prisión preventiva no es una mediada anticipada, ni una sentencia anticipada, es una medida cautelar. ¿Cuál es la finalidad de su pedido? Es que la persona investigada esté sujeta al proceso y nos permita avanzar en la investigación, porque todos tenemos el mismo interés en que las investigaciones avancen en el tiempo más breve, y no haya investigaciones tediosas y dilatorias. No considero que la prisión preventiva sea un anticipo de pena, no lo es, simplemente es cautelar y la finalidad es que el imputado este a disposición de la investigación.

3. ¿Considera que el Ministerio Público está realizando un análisis adecuado para formular sus requerimientos de prisión preventiva, teniendo en cuenta que existen otras medidas menos gravosas que podrían reducir el peligro procesal?

Sí, la opinión pública piensa que los fiscales pedimos prisión preventiva para todo el mundo porque solo esos casos son los que se publicitan, definitivamente, hay una equivocada percepción. Se solicita prisión preventiva sólo cuando concurren los presupuestos. El trabajo de la fiscalía para solicitar prisión preventiva es arduo, para mi hay un manejo adecuado de la prisión preventiva.
4. ¿Se podría incrementar el mínimo requerido como prognosis de pena para excluir así los delitos menos graves?

Considero que no. Lavalla en una temporada se bajó a un año. No compartía tampoco esta medida, porque todos los delitos pasaban la valla de 1 año. El retorno a los 4 años me parece razonable porque divide a los delitos leves, menos graves y graves. Por otro lado, hay que considerar que, los casos en el que el delito supera los 4 años y que en apariencia permite solicitar prisión preventiva, pueden presentar, por ejemplo, circunstancias privilegiadas, que son consideradas por el juez para bajar la pena de 4 años e impedir que se pueda solicitar esta medida.

Es decir, los 4 años se determina haciendo prognosis de pena, tomando en cuenta circunstancias privilegiadas, agravantes, etc. ¿Cuánto más o menos de pena le corresponde a una persona? Ese es el tema, considero que los 4 años son razonables. Ahora, si subiera la valla a 6 años significaría que la medida de prisión preventiva estaría reservada, únicamente, para delitos especialmente graves.

\section{FÉLIX PAOLO ALDEA QUINCHO}

1. ¿El control realizado por parte del juez hacia el requerimiento fiscal de prisión preventiva, garantiza el respeto de las garantías procesales que asisten al imputado?

No todo control judicial, per se, garantiza el respeto de las garantía procesales que asisten al imputado. Si el control al requerimiento se sujeta a los principios constitucionales, consideraríamos que gran parte de las garantías procesales han sido respetadas. Tratándose de un control a un requerimiento que posee como objetivo la privación de libertad, consideramos que debería ser lo más exhaustivo posible, siendo incrementada la rigurosidad, si es realizado por el juez de garantías.

2. ¿Considera que la imposición de la medida de prisión preventiva puede ser interpretada como un indicio de la culpabilidad del imputado y afectar la objetividad y decisión de juez de juzgamiento?

Objetivamente no debería ser interpretado como un indicio de culpabilidad, ni afectar la deci- 
sión del juez de juzgamiento, dado que este último no sería un juez contaminado. En el entendido de que la imposición de la prisión preventiva lo trata el juez de Investigación Preparatoria, en una etapa independiente y anterior a la del juicio. Sin embargo, es imposible negar la dimensión humana de los magistrados; considero muy complicado que con un pronunciamiento de prisión preventiva pueda mantenerse una relación procesal igualitaria, ante el mismo Juez, salvo que este aplicase a carta cabal la regla de compensación que establece la Corte Interamericana en el caso "Norín Catriman vs. Chile", la cual no solo se extiende a la exclusión probatoria sino que evidencia la necesaria aplicación del principio de igualdad de armas y circunstancias.

\section{La Corte IDH ha señalado que la medida} de prisión preventiva debería tener una revisión judicial periódica a fin de verificar la subsistencia de los presupuestos que motivaron su imposición. ¿Considera Ud., que este control podría ser incorporado en nuestro sistema de justicia penal?

Considero que sí, sería un gran aporte para el tratamiento de esta medida. Sobre todo, porque una de las características de la prisión preventiva es la Provisionalidad, es decir, no es una medida definitiva, ergo está sujeta a un cambio. Y uno de los criterios para poder acreditar la variabilidad de la medida sería su revisión judicial periódica. Es necesario resaltar que los pronunciamientos de la Corte $\mathrm{IDH}$, como órgano jurisdiccional, cuentan con una relevancia de vinculación a las decisiones y actuaciones que puedan adoptar los jueces, por amparo de la IV disposición final y transitoria de la Constitución y el artículo $\mathrm{V}$ del título preliminar del Código Procesal Constitucional.

\section{GERMÁN RAMIRO ALATRISTA MUÑIZ:}

\section{1. ¿Puede violentar el derecho constitucional de la libertad personal la prisión preventiva?}

Ningún derecho fundamental, en efecto, puede considerarse ilimitado en su ejercicio. Los límites que a éstos se puedan establecer pueden ser intrínsecos o extrínsecos. Los primeros son aquellos que se deducen de la naturaleza y configuración del derecho en cuestión. Los segundos, los límites extrínsecos, son aquellos que se deducen del ordenamiento jurídico, cuyo fundamento se encuentra en la necesidad de proteger o preservar otros bienes, valores o derechos constitucionales.

La validez de tales límites y, en particular, de la libertad personal, depende de que se encuentren conforme con los principios de razonabilidad y proporcionalidad. Como ha sostenido la Corte Interamericana de Derechos Humanos; nadie puede ser sometido a detención o encarcelamiento por causas y métodos que -aun calificados de legales- puedan reputarse como incompatibles con el respeto a los derechos fundamentales del individuo por ser, entre otras cosas, irrazonables, imprevisibles o faltos de proporcionalidad.

Respecto de la exigencia de una especial motivación de la resolución judicial que decreta el mandato de detención judicial preventiva, señala que:

La necesidad de que las resoluciones judiciales sean motivadas es un principio que informa el ejercicio de la función jurisdiccional y, al mismo tiempo, un derecho constitucional de los justiciables. Mediante ella, por un lado, se garantiza que la administración de justicia y, por otro, que los justiciables puedan ejercer de manera efectiva su derecho de defensa.

Sin embargo, tratándose de la detención judicial preventiva, la exigencia de la motivación en la adopción o el mantenimiento de la medida debe ser más estricta, pues sólo de esa manera es posible despejar la ausencia de arbitrariedad en la decisión judicial, a la vez que con ello se permite evaluar si el juez penal ha obrado de conformidad con la naturaleza excepcional, subsidiaria y proporcional de la detención judicial preventiva.

Dos son, en ese sentido, las características que debe tener la motivación de la detención judicial preventiva. En primer lugar, tiene que ser suficiente, esto es, debe expresar, por sí misma, las condiciones de hecho y de derecho que sirven para dictarla o mantenerla. En segundo término, debe ser razonada, en el sentido de que en ella se observe la ponderación judicial en torno a la concurrencia de todos los aspectos que justifican la adopción de la medida cautelar, pues de otra forma no podría evaluarse si es arbitraria por injustificada. 
2. ¿Cuáles serían las consecuencias de las medidas de prisión preventiva al ser dictadas de manera arbitraria?

Con respecto al uso excesivo de la medida, podemos decir que existe un uso excesivo de la aplicación de esta medida, entiéndase primero que no se aplica el principio excepcional cuya naturaleza está constituida en el excesivo uso, teniendo efectos de ser una condena anticipada y prejuzgando la futura decisión del magistrado.

La aplicación de la prisión preventiva es inaceptable, puesto que existen otro tipo de medidas, las llamadas alternativas, que tienen un origen menos lesivo.

Segundo, existe la nula acción rehabilitadora. - se entienden que generan una serie de problemas de los cuales tenemos:

- El impedimento de ejecutar una acción resocializadora, puesto que aun estando en el centro penitenciario, no se tiene localidad de interno.

- El encarcelamiento, promueve que el procesado conozca y aprenda la conducta delictiva, puesto que no existe una debida separación, los internos y los procesados se encuentran juntos.

- Generan un hacinamiento poblacional generando vulneración de derechos a toda la población carcelaria.

Tercero, tiene un efecto negativo en la impartición de justicia, bajo esta premisa podemos manifestar que existe un uso excesivo por parte de los magistrados de dictar esta medida, en consecuencia, son procesos de larga duración, que afectan no solo a los procesos de medidas preventivas sino a todos los demás existentes, ya que se convierte en un elemento que suma a la carga procesal existente.

Como último considero tiene impacto en el aspecto económico, siendo el estado quien tiene que presupuestar todos estos gastos, entendiendo que la obligación que tiene es la de velar por el desarrollo social y económico de su población".

\section{3. ¿Cuál es su opinión respecto al Acuerdo Plenario $\mathrm{N}^{\circ} 1$ - 2019?}

El Acuerdo Plenario 01- 2019 se emitió por el uso y abuso de la prisión preventiva, con fundamentos basados en la excepcionalidad de la medida, la proporcionalidad de la misma, la prohibición de automatismo, de meras alegaciones a la gravedad de la pena o presunciones e inferencias subjetivas; así como la exigencia de la existencia de indicios objetivos en el caso concreto y la especial motivación, suficiente y razonable, cumpliendo los principios de exhaustividad y congruencia del auto de prisión para evitar arbitrariedad judicial. Es así que la concisión y rigurosidad explicativa que justifiquen las conclusiones fácticas de sospecha fuerte desde el derecho probatorio y jurídico correspondiente. Sustentados en dos motivos: (1) delito grave, y (2) peligrosismo procesal (periculum libertatis, que en el proceso civil se denomina periculum in mora). (Fundamento 34 de Acuerdo Plenario 1- 2019). 